term health impacts of chemical exposure from the oil spill. Firefighters expressed interest in additional safety training, worksite specific knowledge, and environmental monitoring for necessary protection of their health.

Discussion Exposure to environmental disasters may contribute to long-term health and safety consequences. Improved systemic strategies in pre-disaster recovery planning and response preparedness are needed. The potential improvement of occupational health and safety outcomes with necessary environmental monitoring procedures deserve further study.

\section{THE EVOLUTION OF OCCUPATIONAL MEDICINE: A LITERATURE REVIEW}

Leonel Calvano. Universidade Brasil - São Paulo, Brasilia, Brazil

\subsection{6/oemed-2018-ICOHabstracts.536}

The industrial revolution that occurred in the first half of the nineteenth century brought the need of occupational medicine, which originated as a medical specialty in England, to ensure high production. At that time, the workforce reached inhuman levels of production, which required intervention to be guaranteed the minimum conditions for workers. The last 20 years the concern for public health, more rigorous supervision and laws focused on the employee, along with the activities of trade unions and academics began to differentiate the health of occupational health worker, presenting broader approach and greater performance this science. Thus, occupational health and worker health are in the growth and maturation process. From this perspective the objective of this research is to analyse, through bibliographic references, the history and evolution of occupational medicine, stressing the positive aspects from its inception and still faced problems. The research was based on scientific articles, books and especially laws and regulations. The database used in this study was the websites: Google Scholar and Scielo. The keywords used only in Portuguese: History of occupational medicine; Evolution of occupational medicine and laws of occupational medicine. As a result it turns out that the development of occupational health has brought great benefits to both the employee on the company. The occupational physician acts analysing the causes and effects that the way to work or because impossibilities benefits to the employee, whether transient or permanent by analysing the activities carried out by it.

\section{NEW CHALLENGES UNDER NEW PREMISES IN THE PRACTICE OF THE OCCUPATIONAL MEDICINE}

Liliana Rapas. Directorate of Public Health Bucharest/Ministry of Health, Bucharest, Romania

\subsection{6/oemed-2018-ICOHabstracts.537}

Introduction Occupational medicine, science and medical discipline with a practice for more than three centuries, recognises unequal development, linked with the interface human-work/ occupation. This link has an accelerated growth for some companies or health systems that coexist with traditional ambience of other systems, even inside a country.

Material and methods By analogy with the three known axes $0 \mathrm{x}, 0 \mathrm{y}, 0 \mathrm{z}$ while time is the fourth dimension, the analysis is made by considering the four pillars, medicine, science, business, public/social policy for the ten items (the human resources, the specialised vocabulary and communication, the service type, the medical applications for preventive, curative, emergency, recovery, the medical technology-innovation, the types of financing, $\mathrm{Q}$ indicators, networking by sharing the data, the working and development environments, the strategy-law) which customise and differentiate the spherical content of a medical practices with a high turnover of the scientific work dedicated to the health of both the individual and the organisation, the community, the whole society.

Outcomes and comments Even though the initial premises were focused on curative medicine for the workers with occupational diseases (B. Ramazzini, XVIII century), the practice is enlarged, generating polemics, sometimes conflicts, pointing to all the dedicated professionals and/or beneficiaries.

Our study shows that the capacity and the context of the tendering is different on the four pillars and reflects the choice or decision of the professional/doctor to ensure the management of occupational medicine in its entirety or to transfer segments of intervention to other partners. This is reflected concretely for example in standardisation (new approach for time allocation per action), in the health benefits (the surveillance of osteoporosis at workers over $55 \mathrm{~s}$, new hypotheses for the bond between the exposure profile and the occupational disease roadmaps, new design for the medicaltoxicology screening programmes), economic development of the clients (inside digital innovation of the medicine under new workplaces' technologies, mathematical studies for management-administration-finances)-the new themes under new premises for the medical practice in our health system.

\section{THE DYNAMICS OF THE APPEARANCE OF SIGNIFICANT MONOGRAPHS AND MANUALS ON OCCUPATIONAL HEALTH IN RUSSIA}

E Shigan, V Lysukhin. FSBSI Izmerov Research Institute of Occupational Health, Moscow, Russian Federation

\subsection{6/oemed-2018-ICOHabstracts.538}

The history of the appearance of monographs, teaching aids and manuals on $\mathrm{OH}$ in Russia has a little less than two and a half centuries. The first work was the book by A.Bakherakht 'The way to preserve the health of marine workers' (1780). The author dwells in detail on the prevention and treatment seamen`s diseases. A more significant event was the appearance of the book 'Diseases of workers, indicating protective measures' by A.Nikitin (1847), in which he talks in detail about the detrimental effects on health of production factors in more than 120 professions.

Undoubtedly weighty contribution was made by the teaching manuals of F.Erisman 'Professional Hygiene or Hygiene of Mental and Physical Labour' (1877) and V.Svyatlovskiy 'Factory Hygiene' (1891). In them, academic pedagogues dwell on the issues of research and analysis not only of OD, but also the hygienic aspects of the different professions working conditions. An important role was also played by the appearance of the monograph E.Dementyev 'The Factory, What It Gives to the Population and What It Borrowed' (1893), as well as the numerous scientific works of A.Pogozhev and E.Osipov.

Further it is necessary to note the textbook by D.Nikolsky 'The course of professional hygiene' (1907), S.Kaplun's monograph 'Labour and health' (1922), G.Khlopin 'Labour regime and occupational hazards' (1926), N.Vigdorchik's textbook 